American Journal of Environmental Sciences 8 (2): 152-157, 2012

ISSN 1553-345X

(C) 2012 Science Publications

\title{
Pesticide use in South and South-East Asia: Environmental Public Health and Legal Concerns
}

\author{
Abhik Gupta \\ Department of Ecology and Environmental Science, \\ Assam University, Silchar 788011, Assam, India
}

\begin{abstract}
Problem statement: The South and South East Asian countries are characterized by their rich biodiversity as well as cultural diversity. Agricultural expansion for livelihood security is leading to an increase in pesticide application in this region. It has been observed that because of the hot and humid conditions prevalent in this region, most farmers and pesticide applicators do not use proper protective gear, thereby exposing themselves to the hazards of pesticide poisoning. Another important issue is the exposure of infants and children to toxic pesticides, especially in congested urban slums and tenements. Approach: The biodiversity contained in the six biodiversity hotspots located in this region was also at considerable risk from the toxic effects of pesticides from agricultural fields as well as plantations of tea, coffee, rubber, oil palm, which were often present in close proximity of protected areas. Though a large number of countries in this region had ratified and/or signed important international conventions on pesticide manufacture, export-import and trans boundary movements such as the Stockholm, the Rotterdam and the Basel conventions. Results: A large number of hazardous pesticides was still in use in this region and require to be phased out. Information was lacking on the use status of several pesticides in smaller countries, thereby retaining a certain amount of ambiguity. Conclusion: Despite the grave nature of the pesticide use regulation issue in the Asia-Pacific, clear and uniform policy response is lacking in most countries of this region. These issues need to be addressed through dialogues and mutual cooperation both at national as well as international levels.
\end{abstract}

Key words: Agricultural expansion, hazardous pesticides, international conventions, toxic pesticides, protective gear, rich biodiversity, pesticide exposure

\section{INTRODUCTION}

The countries in South and Southeast Asia share a number of common characteristics, while maintaining their distinct geographical, ecological, socio-political and cultural identities. This region harbors a rich biodiversity of plants, animals and microorganisms, which is also paralleled by a multitude of cultures and languages. South Asia-home to one-fifth of the world's population- is also its most densely populated region. Another characteristic feature is that the communities, especially those in the rural areas, live in close proximity to agricultural lands as well as domestic animals. They are, therefore, at a relatively high risk of pesticide exposure. Many communities also reside within or near the forests, often in close contact with the wild biodiversity of plants and animals in protected areas. Plantations of tea, coffee, oil palm and other cash crops also exist in the vicinity of reserve forests and other protected areas. Pesticide applications in the agricultural fields and plantations, therefore, pose a risk to both terrestrial and aquatic biodiversity within these protected areas. South and South East Asian countries are also experiencing rapid and mostly unplanned urban development. Consequently, an increasing number of people are living in cramped and unhygienic conditions in slums, tenements and crowded apartments in rapidly proliferating cities that have poor drainage and lack proper waste disposal, more so hazardous material disposal and management, facilities. Unplanned urban growth in this region has already exacerbated vectorborne diseases, especially dengue and chikungunya (WHO, 2010a). Heavily populated areas in countries such as Bangladesh, India, Indonesia, Myanmar and Thailand have seen resurgence in Malaria and are at a moderate to high risk of contracting malaria. Of the total number of malaria incidences, $44-60 \%$ is caused by Plasmodium falciperum, which also exhibits resistance to chlorquine and other drugs. Vector control has consequently been intensified in all the countries with Indoor Residual Spray as a method of choice (WHO, 2010b). The adverse health effects of such indoor insecticide sprays that still include DDT in several South and South East Asian countries such as 
Am. J. Environ. Sci., 8 (2): 152-157, 2012

Bhutan, India, Nepal and Philippines have not yet been properly assessed. Cockroaches and ants comprise the other important groups of household pests whose infestations are on the rise in most South and South East Asian cities. Cockroach infestations were found to be significantly higher in urban households as compared to their rural counterparts in Penang, Malaysia (Lee et al., 1993). In yet another Malaysian study, a large proportion of households were observed to control ants by aerosol sprays (Lee, 2002). It is my personal observation that television advertisements of ant, mosquito and cockroach control products have become more frequent and colorful and increasingly occupy costly ,prime time' slots in India, probably reflecting their rising demand in the market. The pesticide regulatory mechanisms vary considerably across the countries, most of which face the vexed problem of pesticide residues in food and beverages that besides posing health risks, also threatens the exports of their agricultural products to the developed world. The other important issues include continued sale of old stocks of banned pesticides and spurious or low quality pesticides; deliberate and accidental pesticide poisoning; unsafe storage and improper disposal of used containers; reluctance to use protective clothing and other gears by pesticide applicators and farmers; and overuse of pesticides in agricultural fields and inside houses. In the context of the above, the present study attempts to provide an overview of the environmental, public health and legal-ethical concerns regarding pesticide use in South and South East Asia.

\section{MATERIALS AND METHODS}

The websites of the Stockholm, Rotterdam and Basel Conventions were accessed to download the texts of the Conventions along with the annexure and other pertinent materials. The Food and Agriculture Organization's (FAO) website was accessed for obtaining all available Country Profiles of the South and South East Asian countries; and the website of the Ministry of Agriculture, Government of India, for studying The Insecticides Act, 1968 and The Insecticides Rules, 1971, along with the amendments; and the Pesticides Management Bill, 2008, which repeals the earlier Act. Furthermore, a search for journal articles and authentic reports and other publications by reputed organizations such as the World Bank, FAO, UNEP and others, were made on the UGC-INFONET digital library consortium facility extended to Assam University that provides current as well as archival access to more than 4500 core and peer-reviewed journals and nine bibliographic databases from 23 publishers and aggregators in different disciplines (http://www.inflibnet.ac.in/infonet/). Additionally, search engines like Google scholar and others were also utilized, besides the hard copies stored in the central library of Assam University, Silchar, India.

\section{RESULTS AND DISCUSSION}

Public health concerns: Though the links between pesticides and human health were suspected as early as the 1960s and 1970s, when US epidemiologists observed an unusual rise in Non-Hodgkins Lymphoma in areas of high pesticide use, a number of more recent studies and reviews bring to light some critical health implications of 4 pesticide exposure. Some important examples include loss of peripheral nerve functions in pesticide applicators in New York state, USA, exposed to Organo Phosphate (OP) pesticides (Stokes et al., 1995); possible association between chlorpyrifos exposure and lung cancer in pesticide applicators in Iowa and North Carolina, USA (Lee et al., 2004); loss of several neurobehavioral functions such as visuomotor speed, verbal abstraction, attention and memory in workers in Egyptian cotton fields even at moderate chronic OP exposure (Farahat $e t$ al., 2003) and transient motor and psychiatric problems as well as extrapyramidal symptoms in Brazilian tobacco farmers having chronic, low-dose OP exposure (Salvi et al., 2003). These findings may have particular implications for pesticide applicators and farmers in many South and South East Asian countries, as in the hot and humid conditions of this region, farmers and pesticide applicators are averse to don protective gear in terms of proper clothing, masks, gloves, footwear and headgear. An Indonesian study observed that farmers often used leaking equipment and consequently experienced wetting of bare skin and permeable cotton clothes. They rarely used footwear and gloves and only used a cloth to cover their nose and mouth. Pesticide mixing was mostly done with bare hands. The farmers frequently suffered from hand tremor, twitching eyelids, staggering, pallor, excess sweating, salivation, headache, blurred vision, insomnia, dizziness, fatigue, nausea, vomiting and breathing difficulty (Kishi et al., 1995). Rice farmers in Vietnam's Mekong Delta were also found to be affected by pesticide poisoning which was relatively low in those who avoided the more toxic pesticides and used protective clothing. The affected people often failed to detect the symptoms and manifestations of pesticide toxicity which were revealed by medical tests (Dasgupta et al., 2007). Adoption of a few simple measures such as using good quality sprayers, not smoking during spraying, wearing headgear and changing clothes immediately after spraying significantly reduced the symptoms after spraying in Malaysian farmers (Nordin et al., 2002). In contrast, in 
India, where cotton farmers still apply highly toxic pesticides such as aldicarb, dieldrin, paraquat, etc. with leaking equipment, often against wind drift, wearing cotton shirts and waistcloths ('lungi'), educating farmers alone did not succeed in adoption of safety measures by them. The hot and humid climate could perhaps be one of the reasons for the reluctance to wear protective gear. The women and children are also exposed during weeding, with women also doing the job of mixing pesticides and refilling sprayer tanks. Despite suffering from neurotoxic effects, very few workers sought medical attention. The study also revealed that poor marginal farmers who often worked as professional sprayers were continuously exposed to pesticides and were consequently more affected than the landlords (Mancini et al., 2005). Both the Indonesian and the Indian studies also indicate that the farmers' callousness in pesticide handling may not entirely be due to lack of awareness. A sort of philosophical acceptance of the risks associated with their livelihoods appears to dominate their mindsets and prevent them from taking a pro-active attitude to mitigate the problems. Proper psychological counselling along with designing and popularizing light yet adequately protective clothing at low costs could also contribute significantly towards improving the situation. The effects of pesticide mixtures on human health also need to be studied in more detail, as many farmers in developing countries like Indonesia use a mixture of 3-4 pesticides (Kishi et al., 1995).

Exposure of children to pesticides deserves special attention, especially under the prevailing conditions in low-end urban and rural households in South and South East Asia. Previous studies had shown that infants and toddlers regularly made oral exploration of their surroundings and were in close dermal contact with floors and other surfaces; older children had the habit of playing close to the ground and exhibited hand-to-mouth behaviour and unique dietary habits. These age-groups, especially those in the poor, inner city areas of USA, were, therefore, found to be highly vulnerable to pesticide toxicity (Eskenazi et al., 1999; Landrigan et al., 1999). A study on a group of minority women in New York City revealed that exposure to the organophosphate pesticides chlorpyrifos and diazinon and the carbamate propoxur resulted in lower birth weight and length. These effects were more pronounced in children born before 2001 when the US Environment Protection Agency phased out the domestic use of chlorpyrifos and diazinon. However, the propoxur metabolite 2isopropoxyphenol was also inversely associated with birth length (Whyatt et al., 2004). This is of particular concern for India and perhaps the other countries in the region, where cockroach-killing agents containing propoxur are extensively and often indiscriminately, used in urban households. In the hot and humid climate, bare-bodied or scantily clothed children often crawl on the floor and explore the nooks and crannies, where they are likely to be exposed to the harmful residues. Daniels et al. (1997) in a review of studies published between 1970 and 1996 had shown more than a decade ago that frequent occupational exposure as well as home exposure to pesticides was strongly linked to both childhood leukemea and brain cancer. Another serious concern is that of pesticide self-poisoning, which is estimated to cause around 300,000 deaths every year in Asia-Pacific and yet has failed to evoke any comprehensive public health response (Eddleston et al., 2006).

Environmental concerns: South and South East Asia are among the biodiversity-rich areas of the world. This is reflected in the presence of six of the thirty four Biodiversity Hotspots (BH) of the world, viz., Western Ghats and Sri Lanka, Himalaya, Indo-Burma, Sunderland, Wallacea and Philippines. These hotspots are rich repositories of plant and animal biodiversity that needs to be conserved at all costs. To cite a few instances of this richness, the Indo-5 Burma $\mathrm{BH}$ comprising the north eastern part of India, South Eastern China, Myanmar, Thailand, Laos, Cambodia and Vietnam and encompassing an area of 2 million $\mathrm{m}^{-2}$, has 1300 bird species and several endemic mammals, while the Wallacea and Philippines BH, comprising the numerous islands of eastern Indonesia, Timor and Phiippines, have very high endemism of plants, amphibians and birds. This small region also has four of the seventeen ,megadiverse countries of the world, viz., India, Malaysia, Indonesia and Philippines.

Table 1: Status of stockholm, rotterdam and basel conventions in South and South East Asian countries

\begin{tabular}{llllr}
\hline Country & $\begin{array}{l}\text { Rotterdam } \\
\text { convention }\end{array}$ & $\begin{array}{l}\text { Stockholm } \\
\text { convention }\end{array}$ & $\begin{array}{l}\text { Basel } \\
\text { convention }\end{array}$ \\
\hline Bangladesh & - & + & + \\
Bhutan & - & - & + \\
Cambodia & - & + & + \\
India & + & + & + \\
Indonesia & + & + & + \\
Lao PDR & - & + & - \\
Malaysia & + & + & + \\
Maldives & + & + & + \\
Myanmar & - & + & - \\
Nepal & + & + & + \\
Pakistan & + & + & + \\
Philippines & + & + & + \\
Sri Lanka & + & + & + \\
Thailand & + & - & + \\
Timor-Leste & - & + & + \\
Vietnam & - & + & + \\
\hline
\end{tabular}

+: Ratified and/or signed;-not ratified 
Am. J. Environ. Sci., 8 (2): 152-157, 2012

Table 2: Status of prior informed consent procedure on some major pesticides listed in the Rotterdam convention in South and South East Asia

\begin{tabular}{|c|c|c|c|c|}
\hline \multirow[b]{2}{*}{ Pesticide } & \multicolumn{4}{|l|}{ Countries* } \\
\hline & No Consent & Consent with condition & Consent & No information \\
\hline Chlordane & Ph, Vn, Th, SL, Pak, Nep, Mal, Indi, Lao, Indo & $\mathrm{Bd}$ & & Mya, Bh \\
\hline Lindane & Lao, Indo, Vn, SL, Th, Pak, & Indi, $\mathrm{Ph}, \mathrm{Mal}$ & & Mya, Bh, Bd, Nep \\
\hline Dieldrin & Lao, Indo, Bh, Ph, Vn, Th, Pak, Mal & SL, & Indi, Bd, Nep & Mya \\
\hline DDT & Lao, Indo, Bd, Vn, Th, SL, Pak, & $\mathrm{Ph}$, & Indi, Bh, Nep & Mya, Mal \\
\hline Heptachlor & Indi, Lao, Indo, Bd, Ph, Vn, Th, SL, Pak, Nep, Mal & & & Mya, Bh \\
\hline Dinoseb & Indi, Lao, Bh, Ph, Vn, Th, SL, Pak, Nep, Mal & Mya, Indo, Bd & & \\
\hline $2,4,5-\mathrm{T}$ & Indi, Lao, Indo, Ph, Vn, Th, SL, Pak, Mal & & & Mya, Bh, Bd, Nep \\
\hline EDB & Lao, Indo, Ph, Vn, Th, SL, Pak, Nep, Mal & & Indi, & Mya, Bh, Bd \\
\hline Methyl Parathion & Mya, Lao, Ph, Vn, Th, SL, Mal & Pak, & Indi, & Indo, Bh, Bd, Nep \\
\hline Aldrin & Indi, Lao, Indo, Bh, Bd, Ph, Vn, Th, Pak, Mal & SL, & Nep & Mya, \\
\hline $\mathrm{HCH}$ (Mixed Isomers) & Lao, Indo, Ph, Vn, Th, SL, Pak, & & Indi, Bh, Nep & Mya, Bd, Mal \\
\hline Captafol & Lao, Indo, Ph, Vn, Th, SL, Pak, Mal & Indi, & & Mya, Bh, Bd, Nep \\
\hline Toxaphene & Indi, Lao, Vn, Th, SL, Pak, Mal & Mya, Indo, Bh, Bd, Ph, Nep & & \\
\hline Parathion & Indi, Vn, Th, Pak, Mal & & & $\begin{array}{l}\text { Mya, Lao, Indo, } \\
\text { Bh Bd, Ph,SL, Nep }\end{array}$ \\
\hline Monocrotophos & Vn, Th, Pak & Indi, & Mal & $\begin{array}{l}\text { Mya, Lao, Indo, Bh, } \\
\text { Bd, Ph, SL, Nep }\end{array}$ \\
\hline Methamidophos & Indi, Mya, Ph, Vn, Th, SL, Pak & Mal & Lao & Indo, Bh, Bd, Nep \\
\hline Phosphamidon & Indi, Mya, Lao, Ph, Vn, Th, SL, Pak, Mal & & & Indo, $\mathrm{Bh}, \mathrm{Bd}, \mathrm{Nep}$ \\
\hline
\end{tabular}

However, the forests and the biodiversity contained therein are threatened by agricultural expansion for rice paddies and plantations like that of oil palm, rubber, tea, coffee and others, which are invariably accompanied by applications of a wide range of pesticides including insecticides, herbicides and fungicides. Pesticides were found to affect the structure and function of running water ecosystems in three biogeographic regions of Europe (Schafer et al., 2007). While numerous studies show the acute and chronic toxic effects of pesticides on fish and other aquatic organisms in single species tests, both diversity and productivity of aquatic communities comprising algae, cladocerans, aquatic insects, snails and amphibians, were significantly affected by carbamate and organophosphate insecticides as well as the herbicides glyph sate and 2,4-D (Relyea, 2005a). Similarly, glyph sate, which is believed to be only slightly or moderately toxic to amphibians, was found to cause high mortality to both larval and juvenile amphibians (Relyea, 2005b).

Herbicides like glyph sate and 2, 4-D are extensively applied to control weeds in tea and coffee plantations throughout South and South east Asia. These plantations are mostly close to the protected areas and consequently, pesticide contamination poses a challenge to the conservation of biodiversity in this region, because even if deforestation is checked and aimed to be compensated by reforestation of barren land, the toxic contamination of soil and aquatic ecosystems could decimate or even eliminate the more sensitive and often relatively inconspicuous invertebrates and even vertebrates like fishes and amphibians. The conflict between livelihood security that is likely to lead to the introduction of toxic chemicals and biodiversity conservation could perhaps only be resolved through adoption of organic farming and agro forestry, preferably without seriously compromising the productivity of the systems.

Legal-ethical issues and concerns: Three international conventions govern the manufacture and export-import and other aspects of hazardous chemicals that include many pesticides. Of these, the Stockholm Convention came into force on 17 May, 2004, with an objective to eliminate or reduce the release of twelve Persistent Organic Pollutants (POPs) that included nine pesticides. Through an amendment in May 2009, nine more POPs have been added to the list, of which five are pesticides. The other important convention is the Rotterdam Convention on the Prior Informed Consent Procedure for Certain Hazardous Chemicals and Pesticides in International Trade that entered into force on 24 February 2004. It now has thirty chemicals/groups of chemicals under the prior informed consent procedure after the last revision in 2008, with the addition of all tributyl tin compounds. Table 1 shows the status of ratification and/or signature of these three conventions in South and South East Asia. Of the sixteen countries listed, nine have ratified/signed the Rotterdam Convention, fourteen the Stockholm Convention and thirteen the Basel Convention. However, in the matter of consent or no consent on the import of hazardous pesticides included in the Rotterdam Convention, the 
picture is not so clear and positive, as revealed in Table 2. Large countries with vast agricultural land and inputs like India has still not withdrawn consent for several pesticides like methyl parathion, $\mathrm{HCH}, 1,2-$ Dibromoethane (EDB) and Dieldrin, while it is still using DDT for mosquito control, along with some other countries like Bhutan, Nepal and Philippines (consent with condition). In this context, the wisdom of the advocacy of spraying the inside of houses in malariaprone areas with DDT may be questioned in view of the fact that DDT and DDE residues can remain for a very long time in the body tissues and especially the threat to the well being of infants and children cannot be ignored. It may be worthwhile to find out how some other countries in this region like Sri Lanka, Laos, Bangladesh, Vietnam and Thailand are controlling malaria in their respective territories without using DDT. India has, however, considerably revised its original Insecticides Act, 1968, banned the manufacture and use of more than 25 pesticides and has introduced the Pesticides Management Bill in the Parliament in 2008, which repeals the previous Insecticides Act to provide improved safeguards for public health and environment. It is felt that more frequent dialogues and exchange of information on pesticide use, trade and research at the regional level among the countries of this region can ensure a safer and non-toxic environment vitally necessary for sustainable growth and development of this region of the world.

\section{CONCLUSION}

Pesticides pose a risk to public health and environmental integrity in the biodiversity-rich AsiaPacific. The changing and challenging food security scenario coupled with rapid and unplanned urban growth in this region has led to increased and often indiscriminate use of pesticides in agricultural as well as domestic sectors. These factors are accompanied by lack of health awareness and an indifferent, sometimes fatalistic attitude prevalent among large sections of the populace, especially in the rural areas, The hot and humid climate of many countries in this region also discourages donning of protective gear. The increased risk of both accidental as well as deliberate pesticide poisoning, therefore, not only requires serious policy response, but also definite programmes to ensure proper governance and implementation for taking the policies beyond mere existence on paper. Intergovernmental dialogues in this region ought to include pesticide issue in order to achieve lasting results to ensure a safe nontoxic life for the future progeny in this biologically and culturally diverse region of the world.

\section{REFERENCES}

Dasgupta, S., C. Meisner, D. Wheeler, N.T. Lam and K. Xuyen, 2007. Pesticide poisoning of farm workersimplications of blood test results from Vietnam. Int. J. Hygiene Environ. Health, 210: 121-132. DOI: $10.1016 / j$. .jheh.2006.08.006

Daniels, J.L., A.F. Olshan and D.A. Savitz, 1997. Pesticides and childhood cancers. Environ. Health Perspect., 105: 1068-1077.

Eddleston, M., N.A. Buckley, D. Gunnell, A.H. Dawson and F. Konradsen, 2006. Identification of strategies to prevent death after pesticide selfpoisoning using a Haddon matrix. Injury Prevent. 12: 333-337. DOI: 10.1136/ip.2006.012641

Eskenazi, B., A. Bradman and R. Castorina, 1999. Exposures of children to organophosphate pesticides and their potential adverse health effects. Environ. Health Perspect, 107: 409-419.

Farahat, T.M., G.M. Abdelrasoul, M.M. Amr, M.M. Shebl and F.M. Farahat et al., 2003. Neurobehavioural effects among workers occupationally exposed to organophosphorous pesticides. Occup. Environ. Med., 60: 279-286. DOI: 10.1136/oem.60.4.279

Kishi, M., N. Hirschhorn, M. Djajadisastra, L.N. Satterlee and S. Strowman et al., 1995. Relationship of pesticide spraying to signs and symptoms in Indonesian farmers. Scand. J. Work. Environ. Health, 21: 124-133. DOI: 10.5271/sjweh. 19

Landrigan, P.J., L. Claudio, S.B. Markowitz, G.S. Berkowitz and B.L. Brenner et al., 1999. Pesticides and inner-city children: Exposures, risks, and prevention. Environ. Health Perspect., 107: 431-437.

Lee, C.Y., 2002. Tropical household ants: pest status, species diversity, foraging behavior and baiting studies. In: Proceedings of the 4th International Conference on Urban Pests. pp: 3-18.

Lee, C.Y., N.L. Chong and H.H. Yap, 1993. A study on domiciliary cockroach infestation in Penang, Malaysia. J. Biosci., 4: 95-98.

Lee, W.J., A. Blair, J.A. Hoppin, J.H. Lubin and J.A. Rusiecki et al., 2004. Cancer incidence among pesticide applicators exposed to chlorpyrifos in the agricultural health study. J. Nat. Cancer Institute, 96: 1781- 1789. DOI: 10.1093/jnci/djh324

Mancini, F., A.H.C.V. Bruggen, J.L.S. Jiggins and A.C. Ambatipudi et al., 2005. Acute pesticide poisoning among female and male cotton growers in India. Int. J. Occup. Environ. Health, 11: 221-232.

Nordin, R.B., S. Araki, H. Sato, K. Yokoyama and W.A.M.B. Wan Muda et al., 2002. Effects of safety behaviours with pesticide use on occurrence of acute symptoms in male and female tobaccogrowing malaysian farmers. Ind. Health, 40: 182-190. 
Relyea, R.A., 2005a. The impact of insecticides and herbicides on the biodiversity and productivity of aquatic communities. Ecol. Appl., 15: 618-627. DOI: $10.1890 / 03-5342$

Relyea, R.A., 2005b. The lethal impact of Roundup on aquatic and terrestrial amphibians. Ecol. Appl., 15: 1118-1124. DOI: 10.1890/04-1291

Salvi, R.M., D.R. Lara, E.S. Ghisolfi, L.V. Portela and R.D. Dias et al., 2003. Neuropsychiatric evaluation in subjects chronically exposed to organophosphate pesticides. Toxicol. Sci., 72: 267-271. DOI: 10.1093/toxsci/kfg034

Schafer, R.B., T. Caquet, K. Siimes, R. Mueller and L. Lagadic et al., 2007. Effects of pesticides on community structure and ecosystem functions in agricultural streams of three biogeographical regions in Europe. Sci. Total Environ., 382: 272285. DOI: $10.1016 /$ j.scitotenv.2007.04.040
Stokes, L., A. Stark, E. Marshall and A. Narang, 1995. Neurotoxicity among pesticide applicators exposed to organophosphates. Occup. Environ. Med., 52: 648-653. DOI: 10.1136/oem.52.10.648

WHO, 2010a. Unplanned urbanization a challenge for public health-SEA PR 1503. World Health Organization, Regional office for South East Asia.

WHO, 2010b. Disease burden in SEA region. World Health Organization, Regional office for South East Asia.

Whyatt, R.M., V. Rauh, D.B. Barr, D.E. Camann and H.F. Andrews et al., 2004. Prenatal insecticide exposures and birth weight and length among an urban minority cohort. Environ. Health Perspect., 112: 1125-1132. DOI: 10.1289/ehp.6641 